\title{
Factors associated with first-year discontinuation of Implanon in Upper Egypt: clients' and providers' perspectives
}

\author{
Mirette M Aziz, Amira F El-Gazzar, Omaima Elgibaly
}

Public Health and Community Medicine, Assiut University, Assiut, Egypt

\section{Correspondence to}

Dr Mirette M Aziz, Public Health \& Community Medicine, Assiut University, 71515 Arab Republic of Egypt, Egypt; miretteaziz@ aun.edu.eg

Received 28 June 2017 Revised 4 June 2018 Accepted 4 June 2018 Published Online First 28 June 2018
Check for updates

To cite: Aziz MM, El-

Gazzar AF, Elgibaly O. BMJ Sex Reprod Health

2018:44:260-266.

\begin{abstract}
Background The etonogestrel implant Implanon is a favourable and cost-effective contraceptive method for women in developing countries, and expansion of its use represents a priority for the family planning (FP) programme in Egypt. We studied the factors affecting first-year Implanon discontinuation from clients' and providers' perspectives.
\end{abstract}

Methods We used a mixed quantitativequalitative methodology. We conducted a household survey of Implanon clients and three focus group discussions with FP physicians and directors.

Results We found that $13.5 \%$ of Implanon users discontinued its use in the first year. Survival analysis found that clients who had previously used Implanon (HR 0.36, 95\% Cl 0.15 to 0.88 ) and whose husbands had secondary or a higher level of education (HR $0.36,95 \% \mathrm{Cl} 0.19$ to 0.69 ) were less likely to discontinue Implanon use after the first year, while clients who experienced side effects of Implanon use were more likely to discontinue it (HR 3.6,95\% Cl 1.60 to 8.11). Other causes of discontinuation which emerged in the qualitative analysis were the unjustified advice for Implanon removal by non-gynaecologists, due to unrelated users' complaints, and deficient pre-insertion counselling.

Conclusions Implanon has a low first-year discontinuation rate as compared with other contraceptive methods. FP clients should be given sufficient pre-insertion counselling about side effects of Implanon and duration of protection. Physicians should offer Implanon mainly to clients seeking long-term contraception in order to decrease its discontinuation rate and increase its cost effectiveness.

\section{INTRODUCTION}

Implanon is a subdermally inserted, single-rod implantable contraceptive that

\section{Key messages}

- Implanon has a low first-year discontinuation rate $(13.5 \%)$ as compared with other contraceptive methods in Egypt.

- Side effects, unjustified physicians' advice and desire for pregnancy are the main reasons for first-year discontinuation of Implanon.

- Clients' previous use of Implanon, using Implanon for birth limiting, and higher levels of husbands' education are associated with decreased risk of firstyear discontinuation, while experiencing side effects is the most important predictor of its discontinuation.

contains the progestogen etonogestrel. ${ }^{1}$ It is a favourable contraceptive method for women in developing countries due to its cost effectiveness, long duration, convenience, safety of use while breastfeeding, and high probability of maintaining fertility after discontinuation. ${ }^{1-3}$ In 2006, Implanon was introduced on a small scale by the Ministry of Health and Population (MOHP) in selected hospitals and urban health centres in Egypt at a subsidised price. Since then, there has been an increase in the rates of Implanon provision and uptake, which illustrates that Implanon is a favourable contraceptive method and addresses a need of Egyptian clients (anecdotal evidence, MOHP).

Despite the high initial cost of Implanon, it is cost-effective when used for a number of years. Over the long term, making implants available may reduce the burden on the health system because implants have higher continuation rates compared 
with other contraceptive methods. ${ }^{45}$ Previous studies have found that side effects associated with Implanon use, clients' health concerns, and the desire to become pregnant were the main reasons for Implanon discontinuation. $^{6-9}$

Discontinuation needs to be assessed because Implanon is usually used by women seeking long-term contraception. Also, early discontinuation heightens the risk of unintended pregnancy, which is costly both to individual women and to society. ${ }^{10} 11$

The aim of this study was to measure the frequency of Implanon discontinuation in the first year of use and to understand the factors which might predict early Implanon discontinuation in Upper Egypt from clients' and family planning (FP) providers' perspectives. The findings of the study will help health managers to improve the national FP programmes in Egypt and reduce the economic waste due to method discontinuation.

\section{METHODS}

We used a mixed quantitative and qualitative research method. The study was conducted in Assiut Governorate, Upper Egypt. The quantitative component was a household survey of women who started using Implanon in the year 2014. This criterion was set so that participants would have completed at least 1 year since Implanon insertion, as data collection was done in January 2016. The MOHP provided a list of 1728 FP clients who had Implanon inserted in 10 health districts in 2014. Sample size was calculated by Epi Info six software (CDC, Atlanta, GA, USA). Assuming a discontinuation rate of $25 \%,{ }^{8}$ a sample of 289 will give a precision of $\pm 5 \%$ around this discontinuation rate with 95\% confidence. Eligible women were identified by reviewing the FP registers of Assiut health facilities providing Implanon among other contraceptive methods. We were able to successfully interview 304 eligible Implanon users whose addresses could be reached by data collectors.

All participants were interviewed using a semi-structured questionnaire that was pretested. A pilot study was conducted on $20 \mathrm{FP}$ clients who had been using Implanon for at least 1 year. The questionnaire was tested for any misunderstanding in the vocabulary and the meanings of the questions and for skip patterns. After the pilot interviews, some questions were edited and added. Implanon users were reached with the help of the community health workers of the primary healthcare units in the villages of participants' residence. The sample was collected from 53 villages and seven cities in 10 districts of Assiut Governorate.

The qualitative part of the study included three focus group discussions (FGDs) with a total of 32 participants; two FGDs were conducted with 22 FP physicians providing services at 10 different health facilities providing Implanon, general hospitals and maternal and child health centres in Assiut city and districts. One FGD was conducted with 10 FP directors of directorates of Assiut Governorate.

FGDs were guided by a list of open-ended questions which assessed physicians' knowledge and attitudes about Implanon, its advantages, practice of counselling and follow-up, their management of side effects, experiences with insertion and removal, acceptability of Implanon among FP clients, main causes of discontinuation from physicians' point of view, and their recommendations for improving client compliance.

Formal administrative approval qa obtained from the MOHP to conduct the study and to access the FP registration files. Oral informed consent was sought from women and physicians after explaining the study objectives. Participants' anonymity was preserved.

Data were analysed using SPSS (SPSS Statistics for Windows, Version 21.0; IBM Corp., Armonk, NY, USA). Bivariate analyses were performed, using t-tests and chi-square tests, to identify the significant factors associated with Implanon discontinuation in the first year. The following variables were tested: clients' age, education, husbands' education, parity, source of information about Implanon, received pre-insertion counselling, reason for using Implanon; birth spacing versus limiting and experiencing side effects of Implanon use. Significant variables on bivariate analysis were entered in a Cox regression model. Insertion of Implanon was the starting date, continuation time was counted in months, and the event of interest was the occurrence of discontinuation in the first year of use.

For the qualitative data analysis, we used grounded theory methodology. All codes were clustered into themes and subthemes. Themes were confirmed, modified or discarded from ongoing analysis by re-examination of earlier data and during subsequent data collection. ${ }^{12}$

\section{Patients and public involvement}

There was no patient involvement in this study.

\section{RESULTS}

Sociodemographic characteristics of the survey participants and other relevant information are summarised in table 1.

Previous positive experience with Implanon use whether among relatives/friends (49\%) or previous use by the clients $(13.5 \%)$ were the main reasons for choosing Implanon for contraception by FP clients. Other causes for choosing Implanon included: being an effective method (30.6\%), the desire for preventing pregnancy for long duration (39.5\%), non-suitability of other methods $(25.3 \%)$ and not requiring client intervention (21.7\%). Study participants used Implanon for birth limiting (64.1\%) rather than for birth spacing (35.9\%). 
Table 1 Sociodemographic characteristics of the study participants

\begin{tabular}{|c|c|c|c|}
\hline \multirow[t]{2}{*}{ Variable } & $\begin{array}{l}\text { Continuers } \\
(n=238)\end{array}$ & $\begin{array}{l}\text { Discontinuers } \\
(n=66)\end{array}$ & $\begin{array}{l}\text { Total } \\
(n=304)\end{array}$ \\
\hline & (n (\%)) & $(n(\%))$ & (n (\%) \\
\hline \multicolumn{4}{|l|}{ Age (years) } \\
\hline$<30$ & $81(34.0)$ & $35(53.0)$ & $116(38.2)$ \\
\hline $30-39$ & $115(48.4)$ & $28(42.4)$ & $143(47.0)$ \\
\hline$\geq 40$ & $42(17.6)$ & $3(4.5)$ & $41(13.5)$ \\
\hline Mean (SD) & $32.7(6.8)$ & $29.3(5.6)$ & $32.0(6.7)$ \\
\hline \multicolumn{4}{|l|}{ Educational level } \\
\hline $\begin{array}{l}<\text { Secondary } \\
\text { education }\end{array}$ & $138(58.2)$ & $33(50.0)$ & $171(56.3)$ \\
\hline $\begin{array}{l}\geq \text { Secondary } \\
\text { education }\end{array}$ & $99(41.8)$ & $33(50.0)$ & $132(43.4)$ \\
\hline \multicolumn{4}{|c|}{ Husband educational level } \\
\hline $\begin{array}{l}<\text { Secondary } \\
\text { education }\end{array}$ & $114(48)$ & $36(54.5)$ & $150(49.3)$ \\
\hline $\begin{array}{l}\geq \text { Secondary } \\
\text { education }\end{array}$ & $124(52)$ & $30(45.5)$ & $154(50.7)$ \\
\hline \multicolumn{4}{|l|}{ Residence } \\
\hline Urban & $62(26.1)$ & $18(27.3)$ & $80(26.3)$ \\
\hline Rural & $176(73.9)$ & $48(72.7)$ & $224(73.7)$ \\
\hline \multicolumn{4}{|l|}{ Work status } \\
\hline Work for cash & $25(10.5)$ & $4(6.1)$ & $29(9.5)$ \\
\hline Not working & $213(89.5)$ & $62(93.9)$ & $275(90.5)$ \\
\hline \multicolumn{4}{|l|}{ Parity } \\
\hline 1 & $4(1.7)$ & $3(4.5)$ & $7(2.3)$ \\
\hline 2 & $33(13.9)$ & $16(24.2)$ & $49(16.1)$ \\
\hline 3 & $51(21.4)$ & $16(24.2)$ & $67(22.0)$ \\
\hline 4 & $77(32.4)$ & $14(21.2)$ & $91(29.9)$ \\
\hline $5+$ & $73(30.6)$ & $17(25.8)$ & $90(29.6)$ \\
\hline \multicolumn{4}{|l|}{ Age of youngest child } \\
\hline$<12$ months & $2(0.8)$ & $3(4.6)$ & $5(1.7)$ \\
\hline $12-<24$ months & $102(43.1)$ & $27(41.6)$ & $129(42.7)$ \\
\hline $2+$ years & $133(56.1)$ & $35(53.8)$ & $168(55.6)$ \\
\hline
\end{tabular}

Only $30.0 \%$ of the total study participants received counselling at the health centres before Implanon insertion. Counselled women reported being given information about: advantages of Implanon (51.6\%), side effects (40.7\%), method effectiveness (24.2\%), duration of effectiveness (26.4\%) and maintaining fertility after its discontinuation (11.0\%).

Out of the 304 study participants, there were 66 discontinuers (21.7\%). Almost two-thirds of discontinuers (41/66 discontinuers) discontinued Implanon use in the first year with a calculated first year discontinuation rate of $13.5 \%$ (discontinuation rate $=$ discontinuers/total users x 100).

Discontinuation of Implanon in the first year of use was mainly due to experiencing side effects $(75.6 \%)$.
Table 2 Reasons for discontinuation among Implanon discontinuers

\begin{tabular}{|c|c|c|c|}
\hline \multirow[t]{2}{*}{$\begin{array}{l}\text { Reasons for Implanon } \\
\text { discontinuation }\end{array}$} & $\begin{array}{l}\text { In the first } \\
\text { year }(n=41)\end{array}$ & $\begin{array}{l}\text { After the } \\
\text { first year } \\
(n=25)\end{array}$ & Total $(n=66)$ \\
\hline & $(\mathrm{n}(\%))$ & $(n(\%))$ & $(\mathrm{n}(\%))$ \\
\hline Experiencing side effects & $31(75.6)$ & $15(60.0)$ & $46(69.7)$ \\
\hline $\begin{array}{l}\text { Physicians' advice due to } \\
\text { unrelated complaints }\end{array}$ & $5(12.2)$ & $1(4.0)$ & $6(9.1)$ \\
\hline Desire for pregnancy & $4(9.8)$ & $5(20.0)$ & $9(13.6)$ \\
\hline $\begin{array}{l}\text { Not practising sex due to } \\
\text { husband's travel }\end{array}$ & $1(2.4)$ & $4(16.0)$ & $5(7.6)$ \\
\hline
\end{tabular}

Other causes of first-year discontinuation included: desire for pregnancy $(9.8 \%)$ and not practising sex due to husband's travel (2.4\%). Moreover, $12.2 \%$ of discontinuers were advised by physicians to remove the implant on account of clients' unrelated complaints (table 2).

Regarding the experienced side effects which caused Implanon discontinuation, severe and prolonged bleeding were the most frequently reported side effects (64.5\%), followed by arm pain at the site of insertion (19.3\%), and other non-specific complaints such as weight gain $(9.7 \%)$ and headache $(6.5 \%)$.

The daily activities of $43.7 \%$ of Implanon clients who reported menstrual side effects were negatively affected, as bleeding interfered with their sexual life, decreased their ability to pray and limited their mobility.

Table 3 shows that Implanon discontinuation was significantly associated with clients' age, their husbands' level of education, previous use of Implanon and experiencing side effects of Implanon use.

Table 4 shows Cox regression survival analysis examining the factors that predict Implanon discontinuation. Survival analysis found that clients who had previously used Implanon (HR $0.36,95 \%$ CI 0.15 to 0.88 ) and whose husbands had secondary or a higher level of education (HR $0.36,95 \%$ CI 0.19 to 0.69 ) were less likely to discontinue Implanon use after the first year, while clients who experienced side effects of Implanon use were more likely to discontinue its use (HR 3.6, 95\% CI 1.60 to 8.11). Clients' age and use of Implanon for birth limiting were not statistically significant in the multivariate model (figures 1 and 2).

\section{Qualitative study findings}

Implanon has high continuation rates

Most FP physicians mentioned that Implanon has a high continuation rate. This was attributed to Implanon's advantages, the most important of which for clients are effectiveness for long duration and needing minimal follow-up.

"The capsule remains in the woman's arm for a long duration, she usually forgets about it and this 


\begin{tabular}{|c|c|c|c|c|}
\hline \multirow[t]{2}{*}{ Variables } & \multirow{2}{*}{$\begin{array}{l}\text { Continuers }(\mathrm{n}=263) \\
(\mathrm{n}(\%))\end{array}$} & \multirow{2}{*}{$\begin{array}{l}\text { Discontinuers }(n=41) \\
(n(\%))\end{array}$} & \multirow[t]{2}{*}{ Significance test } & \multirow[t]{2}{*}{$P$ values } \\
\hline & & & & \\
\hline Age (years) & & & & 0.031 \\
\hline Mean (SD) & $29.93(5.6)$ & $32.3(6.8)$ & $t=-2.15$ & \\
\hline Wife educational level & & & $\chi^{2}=1.07$ & 0.322 \\
\hline$<$ Secondaryeducation & $151(57.4)$ & $20(48.8)$ & & \\
\hline$\geq$ Secondary education & $112(42.6)$ & $21(51.2)$ & & \\
\hline Husband educational level & & & $\chi^{2}=6.8$ & 0.009 \\
\hline$<$ Secondaryeducation & $122(46.4)$ & $28(68.3)$ & & \\
\hline$\geq$ Secondary education & $141(53.6)$ & $13(31.7)$ & & \\
\hline Parity & & & $\chi^{2}=1.4$ & 0.245 \\
\hline$\leq 3$ & $103(39.2)$ & $20(48.8)$ & & \\
\hline$>3$ & $160(60.8)$ & $21(51.2)$ & & \\
\hline Source of information about Implanon & & & $\chi^{2}=0.14$ & 0.711 \\
\hline Healthcare providers & $27(10.3)$ & $5(12.2)$ & & \\
\hline Relatives/friends & $236(89.7)$ & $36(87.8)$ & & \\
\hline Previous use of Implanon & & & $\chi^{2}=7.6$ & 0.006 \\
\hline Yes & $96(36.5)$ & $6(14.6)$ & & \\
\hline No & $167(63.5)$ & $35(85.4)$ & & \\
\hline Reason for using Implanon & & & $\chi^{2}=6.5$ & 0.013 \\
\hline Birth spacing & $87(33.1)$ & $22(53.6)$ & & \\
\hline Birth limiting & $176(66.9)$ & $19(46.3)$ & & \\
\hline Received pre-insertion counselling & & & $\chi^{2}=0.01$ & 0.896 \\
\hline Yes & $79(30.0)$ & $12(29.3)$ & & \\
\hline No & $184(70.0)$ & $29(70.7)$ & & \\
\hline Experienced side effects with Implanon & & & $\chi^{2}=12.5$ & 0.001 \\
\hline Yes & $141(53.6)$ & $34(82.9)$ & & \\
\hline No & $122(46.4)$ & $7(17.1)$ & & \\
\hline
\end{tabular}

comforts her." [Female FP physician, age 47 years, general hospital, Assiut city]

Implanon is a favourable contraceptive method for rural women The preference of Implanon by rural women was attributed to some cultural values in the rural communities such as the influence of relatives' and neighbours' contraceptive experiences, the perception of safety of the contraceptive method so long as its location is distant from the genitals, avoidance of contraceptive methods which require vaginal examination, and favouring amenorrhea which can be associated with use of this method.

\begin{tabular}{|c|c|c|}
\hline Variable & HR & $95 \% \mathrm{Cl}$ \\
\hline Experience of side effects & 3.60 & 1.60 to 8.11 \\
\hline Using Implanon for birth limiting & 0.53 & 0.26 to 1.1 \\
\hline Previous clients' Implanon use & 0.36 & 0.15 to 0.88 \\
\hline $\begin{array}{l}\text { Husband education } \\
\text { (secondary education and above) }\end{array}$ & 0.36 & 0.19 to 0.69 \\
\hline Clients' age & 0.99 & 0.93 to 1.05 \\
\hline
\end{tabular}

"Women in rural areas favour the capsule rather than the intrauterine device (IUD), just give them a contraceptive method other than the IUD and they would love it." [FP director, age 44 years, rural Assiut]

Side effects and desire for pregnancy are the most important causes of Implanon discontinuation

Side effects, especially menstrual disturbances, were the main causes of Implanon discontinuation in the first year, while discontinuation for getting pregnant was usually observed after the first year.

"The clients who ask for Implanon removal after the first year, usually do so as they want to get pregnant, especially when they know that it can be removed at any time, but removal for experiencing side effects usually occurs after a month or two from insertion." [Obstetrician/gynaecologist, age 55 years, maternal and child health centre, Assiut city]

Some users discontinue Implanon due to unjustified physicians' advice Many physicians, especially in orthopaedics, claimed that Implanon was resposible for non-specific users' complaints, such as bone pain or varices, and 


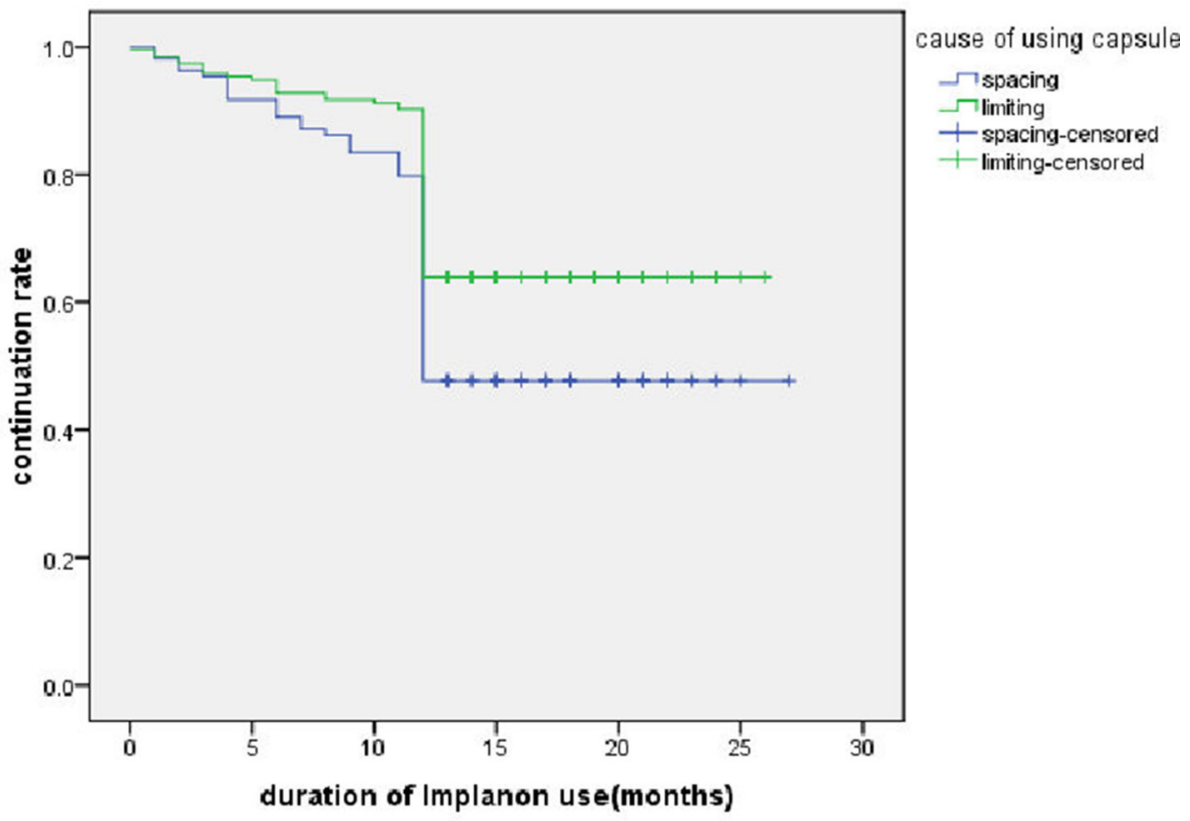

Figure 1 Survival plot according to the reason for using Implanon; mean survival time (continuation time) limiting versus spacing.

recommended Implanon discontinuation when this was not in fact indicated.

"Some physicians may attribute headache, bone pain, breastfeeding problems to the capsule. Yes, women say the physician told me I should remove it, and of course she trusts his opinion." [Female FP physician, age 47 years, general hospital, Assiut city]

Discontinuation is frequently observed among non-counselled clients Most physicians mentioned that although counselling is an essential component of FP services, they may provide deficient counselling due to shortage of time and crowded FP clinics. Deficient counselling may result in discontinuation because the clients may perceive the long duration of bleeding as unexpected and prolonged.

"Counselled women wouldn't ask for Implanon removal with the first encountered side effect. They may tolerate the occurrence of menstrual irregularities as they are previously informed about [them]." [FP director, age 56 years, Assiut Governorate]

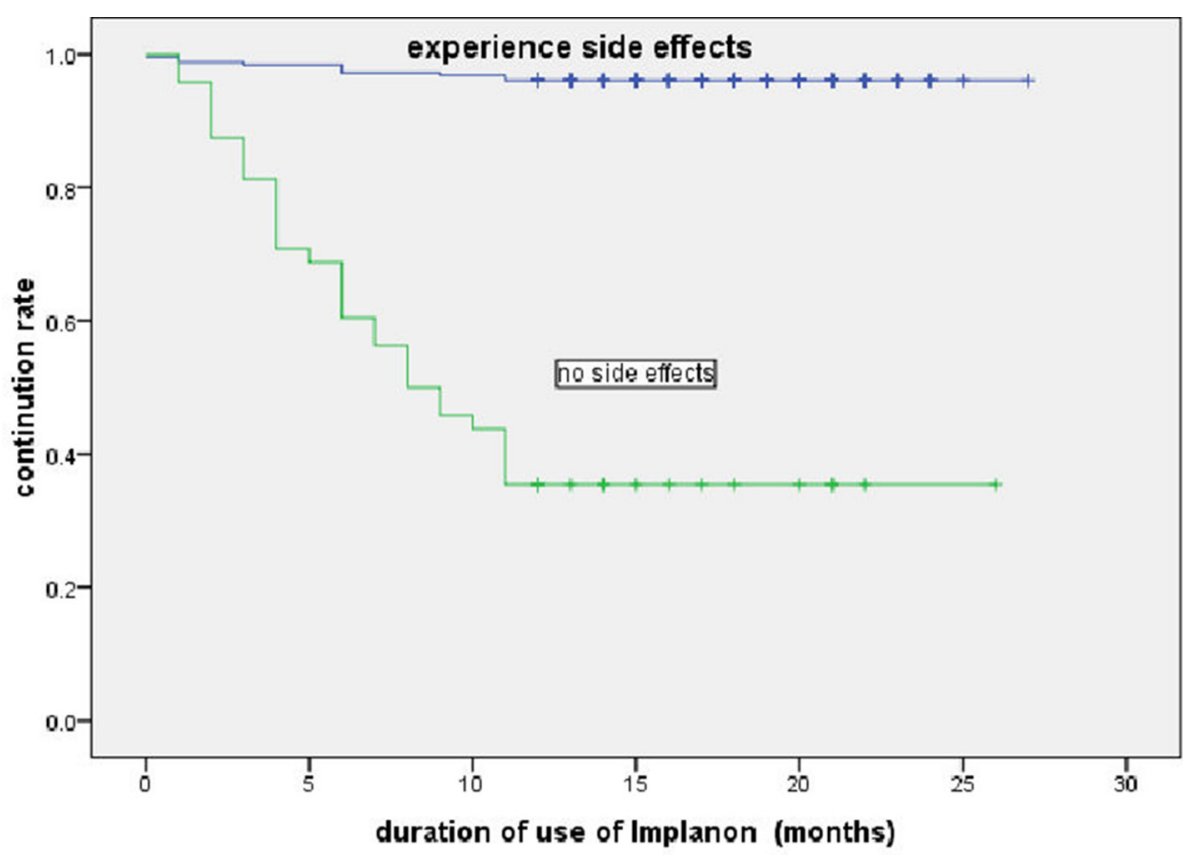

Figure 2 Survival plot according to the reason for using Implanon; mean survival time (continuation time) experiencing side effects versus not experiencing side effects. 


\section{DISCUSSION}

Introducing a new contraceptive method into an ongoing FP programme requires careful planning and implementation, and follow-up of the uptake and discontinuation rates. Discontinuation rates of contraceptives are important indicators for FP programme directors. The results of this study might reflect deficiencies in the quality of services and will help FP leaders to plan for the required interventions to improve the method continuation rate. Implanon is a relatively recent long-acting contraceptive method which provides effective, forgettable contraception for 3 years and does not require follow-up or clients' intervention. These advantages make it highly suitable for Egyptian women with low levels of education and reproductive health awareness. ${ }^{13}$

We found that $13.5 \%$ of Implanon users in Assiut Governorate discontinued its use in the first year, which is higher than the rates in other developing countries such as Zimbabwe, Senegal and Nigeria. ${ }^{14}$

Consistent with previous studies, we found that side effects, especially menstrual irregularities, were the most important reasons for clients discontinuing Implanon use. ${ }^{8} 15$

However, a previous study in Egypt found that despite experiencing menstrual irregularities, among FP clients using injectables, IUDs and Implanon, those using Implanon had the lowest discontinuation rate. ${ }^{16}$

Implanon's perceived advantages greatly outweigh the nuisance effects. ${ }^{17} 18$ Moreover, the menstrual side effects of Implanon are not as high as with other progestogen-only contraceptives. ${ }^{19}$ So, if women have sufficient pre-insertion counselling about the expected bleeding pattern and this is accepted by clients, this will have a major impact on lowering the discontinuation rates. ${ }^{1620}$

We found that although menstrual disruption had no serious effects on health, women discontinued Implanon because the bleeding disturbances interfered with daily activities, such as Muslim women's prayers and their sexual relationship with their husbands. ${ }^{17}$

Consistent with another study, previous clients' Implanon use was one of the factors that prolonged the duration of method use, ${ }^{21}$ which indicates that women who accepted the Implanon side effects during the 3 years of previous use are the best clients for using Implanon.

We also found that husbands' education was a significant predictor of prolonging the duration of Implanon use. This can be attributed to the educated husbands' social norms favouring small family size, and supporting $\mathrm{FP}^{22} 23$

Other indirect causes of discontinuation emerged in the qualitative study, such as physicians' recommendations for Implanon removal due to misperception of unrelated side effects, especially when they are non-gynaecologists. This is consistent with previous research that found that the quality of information women receive from their providers about contraceptive methods was an important contributing factor to the underuse of contraceptive methods. ${ }^{24} 25$

The qualitative part of the study also revealed that Implanon was preferred by rural women who have the highest total fertility rate in Egypt (4.1). ${ }^{26}$ Consequently Implanon could have the potential to meet these women's unmet contraceptive needs and help to reduce their high fertility rate. This could be applicable in other countries with similar conservative cultures.

Our study has provided an insight into the adequacy of the provided FP services, as it revealed deficient client registration and counselling. The deficient registration of clients' personal data would ultimately hinder clients' follow-up and side effect management, which would prevent or delay discontinuation.

Strengths of this study were that it was a community-based study in one of the largest Governorates of Upper Egypt, with data collected from urban and rural areas and with mixed methodology. However, we could not obtain a random sample of users for the year 2014, due to deficient registration files with incomplete addresses and client names.

\section{CONCLUSIONS}

We have shown that Implanon is a favourable contraceptive method for Egyptian women, especially those residing in rural areas. However, Implanon discontinuation could be attributed not only to method factors but also to provider and health system factors. Improving FP counselling services and offering Implanon mainly to clients seeking long-term contraception would have a great impact on reducing Implanon discontinuation and increasing its cost effectiveness.

Improving the FP knowledge of physicians of different specialties about contraceptive side effects and their management would also limit physicians' recommendations that women discontinue Implanon use on account of non-specific side effects.

Acknowledgements The authors would like to thank the UNFPA for funding the study, and the Egypt MOHP and Assiut FP health sector for their support and facilitating data collection.

Contributors All the authors contributed to the manuscript as follows: MMA designed the protocol, study tools, and obtained IRB approval. Both MMA and AFE-G were responsible for data collection, data entry, synthesis and analysis of both qualitative and quantitative data, as well as writing the final manuscript. MMA and AFE-G are the guarantors of this manuscript. OE conceived the idea of the study and revised the protocol, tools and manuscript.

Funding This research was funded by United Nations Population Fund.

Competing interests None declared.

Patient consent Not required.

Ethics approval This study was approved by the Ethical Committee of Assiut University. 
Provenance and peer review Not commissioned; externally peer reviewed.

(C) Article author(s) (or their employer(s) unless otherwise stated in the text of the article) 2018. All rights reserved. No commercial use is permitted unless otherwise expressly granted.

\section{REFERENCES}

1 Roberts AO, Morhason-Bello IO, Okunlola MA, et al. Profile of Implanon ${ }^{\circledR}$ acceptors and pattern of side effects. J Reprod Contracept 2015;26:46-52.

2 McDonald-Mosley R, Burke AE. Contraceptive implants. Semin Reprod Med 2010;28:110-7.

3 Hubacher D, Olawo A, Manduku C, et al. Factors associated with uptake of subdermal contraceptive implants in a young Kenyan population. Contraception 2011;84:413-7.

4 Lipetz C, Phillips CJ, Fleming CF. The cost-effectiveness of a long-acting reversible contraceptive (Implanon) relative to oral contraception in a community setting. Contraception 2009;79:304-9.

5 Steiner MJ, Lopez LM, Grimes DA, et al. Sino-implant (II)levonorgestrel-releasing two-rod implant: systematic review of the randomized controlled trials. Contraception 2010;81:197-201.

6 Harvey C, Seib C, Lucke J. Continuation rates and reasons for removal among Implanon users accessing two family planning clinics in Queensland, Australia. Contraception 2009;80:527-32.

7 Agrawal A, Robinson C. An assessment of the first 3 years' use of Implanon in Luton. J Fam Plann Reprod Health Care 2005;31:310-2.

8 UNFPA. Implanon use pattern among Ministry of Health and Population clients 2008-2012. 2013 http://egypt.unfpa.org/ english/publication/56b9df9a-da21-4905- 94ef-39d127622fc4 (accessed 8 Oct 2015).

9 Lakha F, Glasier AF. Continuation rates of Implanon in the UK: data from an observational study in a clinical setting. Contraception 2006;74:287-9.

10 Frost JJ, Singh S, Finer LB. U.S. women's one-year contraceptive use patterns, 2004. Perspect Sex Reprod Health 2007;39:48-55.

11 Blanc AK, Curtis S, Croft T. Does contraceptive discontinuation matter?: quality of care and fertility consequences. MEASURE Evaluation Technical Report Series 1999. https://www.measureevaluation.org/resources/ publications/wp-99-14

12 Glaser B, Strauss A. The discovery of grounded theory: strategies for qualitative research. New York, NY: Aldine, 1967.
13 Ezegwui HU, Ikeako LC, Ishiekwene CI, et al. The discontinuation rate and reasons for discontinuation of Implanon at the family planning clinic of University of Nigeria Teaching Hospital (UNTH) Enugu, Nigeria. Niger J Med 2011;20:448-50.

14 Aradhya KW. A promising future for contraceptive implants in Africa. Medical Education Resource Africa 2007;30:3-4.

15 Mutihir JT, Dd N. One-year experience with Implanon sub-dermal implants in Jos, Nigeria. Niger J Clin Pract 2010;13:28-31.

16 Tolley E, Loza S, Kafafi L, et al. The impact of menstrual side effects on contraceptive discontinuation: findings from a longitudinal study in Cairo, Egypt. Int Fam Plan Perspect 2005;31:15-23.

17 Birhane K, Hagos S, Fantahun M. Early discontinuation of Implanon and its associated factors among women who ever used Implanon in Ofla District, Tigray, Northern Ethiopia: International Journal of Pharma Sciences and Research, 2015.

18 Madugu NH, Abdul MA, Bawa U, et al. Uptake of hormonal implants contraceptive in Zaria, Northern Nigeria. Open J Obstet Gynecol 2015;05:268-73.

19 Funk S, Miller MM, Mishell DR, et al. Safety and efficacy of Implanon, a single-rod implantable contraceptive containing etonogestrel. Contraception 2005;71:319-26.

20 Halpern V, Grimes DA, Lopez L, et al. Strategies to improve adherence and acceptability of hormonal methods for contraception. Cochrane Database Syst Rev 2006:CD004317.

21 Weisberg E, Fraser I. Australian women's experience with Implanon. Aust Fam Physician 2005;34:694-6.

22 Okwor EU, Olaseha IO. Married men's perception about spousal use of modern contraceptives: a qualitative study in Ibadan northwest local government area, Southwest Nigeria. Int Q Community Health Educ 2010;30:223-38.

23 Population Reference Bureau. Is education the best contraceptive? 2000 http://www.prb.org/pdf/IsEducatContracept_Eng.pdf (accessed 8 Oct 2015).

24 Moos MK, Bartholomew NE, Lohr KN. Counseling in the clinical setting to prevent unintended pregnancy: an evidencebased research agenda. Contraception 2003;67:115-32.

25 RamaRao S, Lacuesta M, Costello M, et al. The link between quality of care and contraceptive use. Int Fam Plan Perspect 2003;29:76-83.

26 EDHS. El-Zanaty and Associates [Egypt], and ICF International. Egypt Demographic and Health Survey 2014. Cairo, Egypt and Rockville, Maryland, USA: Ministry of Health and Population and ICF International, 2015. 